\title{
LACTATIONAL PERFORMANCE OF MANIPURI WOMEN
}

\author{
Luwang N C*, Singh T A*, Devi L I"
}

\section{ABSTRACT}

A study was conducted to measure the volume of breast milk output of 26 lactating women and to estimate the period of its adequacy as the sole food for the infants. Child-mother pairs were selected on voluntary basis from amongst mothers who delivered in the Regional Institute of Medical Sciences Hospital, Imphal, Manipur (India). Daily volume of breast milk output was measured by test weighing method by weighing the infants before and after each breast feeding in $\mathbf{2 4}$ hours period at different stages of lactation.

Daily mean volume of milk output was in the range of $500-550 \mathrm{ml}$ at the $1 \mathrm{st}$ month, $590-600 \mathrm{ml}$ at 2-3 months, $520-560 \mathrm{ml}$ at 4 months, $450-500 \mathrm{ml}$ at 5 months, $420 \mathrm{ml}$ at 6 months and $340 \mathrm{ml}$ at 7 months. Period of adequacy of breast milk for the infant was judged by estimation of the proportion of energy the child is getting from the mother in term of its energy requirement for its weight. About $60-95 \%$ of infants received less than $80 \%$ of energy demand from the mother at $1-3$ months of age and $60-80 \%$ received less than $60 \%$ of energy requirement after completion of 4 months of age. The present study demonstrated that mother's breast milk is adequate as sole for the infants upto 4-5 months of age.

Key Words: Breast milk output, test weighing, adequacy of breast milk, energy demand.

\section{INTRODUCTION}

There had been varied opinion about the nutritional adequacy of breast feeding. . $2,3,4,5,6$ It has now been accepted that breast milk can meet the nutritional need of the child upto 4 months of age. ${ }^{7.8}$ Most reports in this subject are based on physical growth of breast-fed infants. It is apparent that the ultimate test of adequacy of breast milk will be reflected by examination of volume of milk and supply of food by the mother to the infant. Unfortunately, such data are scanty in the literature and difficult to compare because of differences in sampling and techniques and also because of regional variations. In an attempt to fill the gap in knowledge and for utilisation in the assessment of infant nutrition, the present investigation was undertaken to estimate the quantity of breast milk output of Manipuri women at different stages of lactation and to examine the period of adequacy of breast milk as the sole food for the infant to meet its energy demand to maintain growth and development.

\section{MATERIAL AND METHODS}

The study was conducted in the Imphal Municipal area of Manipur state during the period of June 1995 to September 1996. Though the original plan was to select child-mother pairs by simple random sample of normal deliveries at the Regional Institute of Medical Sciences Hospital, Imphal, it was practically not feasible. Mother who volunteer themselves

* Nepalgunj Medical College, Chisapani, Banke, Nepal.

** Regional Institute of Medical Sciences, Imphal, Manipur, India.

Address for correspondence : Dr. Nimai Chand Luwang

5/VI Babupara,

Imphal 795001, Manipur, India.

Email:ncluwang@yahoo.com 
were selected and included in the study, most being either friends or relatives of the two Field Supervisors employed in the project. Mothers who volunteer for inclusion as subjects of study and agreed in the follow up examinations were selected and included in the study. All the mothers had deliveries in the Regional Institute of Medical Sciences Hospital. Childmother pairs were registered within three days of delivery. Information of the mother, husband, family, socioeconomic condition, obstetrical history etc. were also recorded in a predesigned, pretested proforma schedule. Information regarding delivery, feeding history, birth weight were also recorded. Mothers who had established breast-feeding in the first week were included in the study. Mother or infants who became sick anytime during the follow up were dropped from the study. Mother and their family members were briefed and motivated regarding follow up examinations and regular home visits to be made by the field workers.

Estimation of volume of milk intake was done by test weighing method. In order to estimate the actual volume of breast milk intake of infant, it has been ensured that there was no change in the psycho-environmental conditions that might affect breast feeding. Mothers were allowed to feed on demand and measurements were taken at home. Milk intake by the infants were measured by taking weight of the infants before and after each feed over a 24 hour period, the difference in weight being the amount of milk ingested by the infant. Weight of infants were measured on a beam balance which can measure upto 10 gms. accuracy (manufactured by the CMS weighing equipments LTD., London). To carry out the determination of amount of breast milk intake of infants in 24 hours period, field workers made home visits of child-mother pair families and lived with them for the whole day for taking weight measurements. Two supervisors, graduates in Nutrition and Estimation of volume of milk intake was done by test weighing method. In order to estimate the actual volume of breast milk intake of infant, it has been ensured that there was no change in the psycho-environmental conditions that might affect breast feeding. Mothers were allowed to feed on demand and measurements were taken at home. Milk intake by the infants were measured by taking weight of the infants before and after each feed over a 24 hour period, the difference in weight being the amount of milk ingested by the infant. Weight of infants were measured on a beam balance which can measure upto 10 gms accuracy (manufactured by the CMS weighing equipments LTD., London). To carry out the determination of amount of breast milk intake of infants in 24 hours period, field workers made home visits of child-mother pair families and lived with them for the whole day for taking weight measurements. Two supervisors, graduates in Nutrition and Dietetics and six field workers, matriculate trained in Female Health Worker's course were employed for this purpose. The quantity of breast milk consumed by the infants in 24 hours were measured at weekly intervals for the first four weeks of lactation and at fortnightly intervals thereafter upto 7 months of age.

In the beginning of the study, 41 child-mother pairs were registered and included in the study. However, only 26 could be followed till the completion of the study. The present study has been one of the longitudinal panel survey making regular follow up examinations of the child-mother pairs from the first week to 28 weeks of lactation. However, there were dropouts in between and some could not be followed till the end due to reasons like outstation of the child-mother pairs, lack of cooperation from family members, sickness of child and/or mother, etc. The information were analysed by using a semilongitudinal sample.

\section{RESULTS}

\section{Milk intake}

Table I shows the mean and standard deviation of quantity of milk intake by infants at different stages of lactation. It was observed that milk intake was maximum at ages of 8-14 weeks. Milk output slowly increased from 1st week onwards reaching maximum at age 10-14 weeks and showing a declining trend thereafter. Mean daily milk intake was $507 \mathrm{ml}$ at 1 st week of age increasing to $562 \mathrm{ml}$ at completion of $1 \mathrm{st}$ month, $606 \mathrm{ml}$ at 3 months, $522 \mathrm{ml}$ at 4 months of age. Thereafter, mean daily milk intake decreased slowly showing $455 \mathrm{ml}$ at 5 months, $422 \mathrm{ml}$ at 6 months and $340 \mathrm{ml}$ at 7 months of age. Mean daily breast milk intake ranged from $500-550 \mathrm{ml}$ in the first month and 590-600 $\mathrm{ml}$ at 2-3 months of age of infants. There was a sharp decline in the mean breast milk intake after completion of 4 months of age of infants.

\section{Adequacy of breast milk for the infant}

Tables II and III shows the distribution of infants receiving less than $80 \%$ and $60 \%$ of energy requirement respectively for its weight from the mother's breast milk at different stages of lactation. It was observed that 60-90 percent of infants received less than $80 \%$ of energy requirement from mother's breast milk from 1-3 months. All infants received less than $80 \%$ of energy requirement from mother from 4 months of age onwards. Approximately, 60-80 percent infants received less than $60 \%$ of energy requirement for their weights from mother's breast milk at 3-4 months of age. Almost all infants received less than $60 \%$ of energy requirement from mothers from 5 months onwards. 
Table I : Breast milk intake (ml.) at different stages of lactation. 